Recebido em 08/2017. Aceito para publicação em 12/2017.

\title{
A EXPLORAÇÃo de AREIA NA REGIÃo METROPOLITANA do VALE dO PARAÍBA E LITORAL NORTE E A GESTÃO MINERÁRIA NOS MUNICÍPIOS DE SÃO JOSÉ DOS CAMPOS E JACAREÍ - SP
}

\author{
SAND EXPLOITATION IN THE METROPOLITAN REGION OF THE PARAÍBA \\ VALLEY AND NORTH COAST AND THE EXPLOITATION MANAGEMENT IN THE \\ MUNICIPALITIES OF SÃO JOSÉ DOS CAMPOS AND JACAREÍ - SP.
}

\author{
Giorgia Yoshiko Rossignolo Suzumura Becker ${ }^{1}$ \\ Mário Valério Filho²
}

Resumo: O processo acelerado de urbanização, em meados do século $X X$, no Brasil, trouxe o aumento na demanda da extração de areia, uma realidade que se repete nos municípios de Jacareí e São José dos Campos, pertencentes à Sub-Região 1 da Região Metropolitana do Vale do Paraíba e Litoral Norte RMVPLN. A exploração desse recurso mineral costuma gerar um grande conflito socioeconômico ambiental, pois a sociedade busca esses recursos para suprir suas necessidades, mas, por outro, lado a população que habita próximo a essas áreas de exploração sofre diretamente com o impacto gerado. Este artigo aborda a problemática da exploração de areia nos municípios de Jacareí e São José dos Campos, pois, mesmo fazendo parte de uma mesma Região Metropolitana, não há políticas voltadas para um interesse comum dos municípios, uma vez que devido a legislações municipais diferentes, atuam de forma distinta quanto à exploração da areia em seu território. Os estudos bibliográficos e análises das legislações competentes geraram dados levantados que permitiram identificar que, em São José dos Campos, existem vários conflitos entre a atividade mineradora e o uso e ocupação do solo, sendo essa atividade proibida desde a Lei Orgânica de 1990. Já, em Jacareí, município vizinho, a legislação permite a exploração de areia em suas terras.

Palavras-chave: Planejamento urbano e regional; exploração de areia; gestão minerária; Jacareí; São José dos Campos.

Abstract: The accelerated urbanization process in the mid-twentieth century in Brazil brought the increase in the demand of sand extraction, a reality that is repeated in the cities of Jacarei and São José dos Campos, belonging to the Sub-Region 1 RMVPLN. The exploitation of this mineral resource usually generates a huge socio-economic and environmental conflict, as the society seeks these resources to meet their needs; on the other hand, the population living next to these exploration areas suffers directly from the impact generated. This article approaches the problem of sand exploitation in the cities of Jacareí and São José dos Campos, for even being part of the same metropolitan area, there aren't policies aimed at a common interest of the municipalities, since due to different local legislations, they act differently in relation to sand exploitation in their territory. The bibliographic studies and the analysis of the relevant legislation generated data collected that allowed the identification that in São José dos Campos there are many conflicts between the mining activity and land use and occupation, and this activity has been prohibited since the Organic Law of 1990. Conversely, in Jacareí, a neighbor municipality, the legislation allows sand exploitation on the land. Keywords: Urban and regional planning; sand exploration; mining management; Jacareí; São José dos Campos.

\footnotetext{
1 Mestra em Planejamento Urbano e Regional pela Universidade do Vale do Paraíba - Univap/Instituto Federal de Educação, Ciência e Tecnologia de São Paulo, SP, Brasil. E-mail: giorgiayrs@gmail.com.

2 Doutor em Agronomia pela Universidade de São Paulo. Professor Pesquisador da Universidade do Vale do Paraíba - Univap, SP, Brasil. E-mail: mvalerio@univap.br.
} 


\section{INTRODUÇÃO}

A areia é um recurso natural, fonte de matéria-prima básica necessária à construção civil. Seu uso está ligado diretamente ao processo de crescimento urbano e associado à demanda populacional.

As questões relativas à exploração de areia têm impacto diversificado no cenário socioeconômico dos municípios, situação agravada pelo crescimento das cidades, que intensifica a exploração desse recurso. A problemática, em relação ao consumo desse minério, relaciona-se a impactos diversos, sendo estes ambientais, topográficos, químicos, físicos e biológicos, que, consequentemente, geram o desequilíbrio da flora e fauna das áreas afetadas.

Mesmo havendo demarcação legal para a exploração da areia, alguns mineradores extrapolam o uso dessas áreas para atender à demanda do mercado atual, gerando grande impacto no meio ambiente, resultante da falta de fiscalização adequada. Diante desse contexto, identifica-se que os recursos estão se tornando escassos, sobretudo os não renováveis, como no caso da areia.

Como os grandes centros urbanos são os principais consumidores desse minério, as explorações das cavas de areia ocorrem geralmente próximas dessas áreas, pois dispõem de melhor infraestrutura viária, fato que facilita o transporte do produto, ao mesmo tempo em que minimiza o valor do frete até o revendedor.

De acordo com Rondino (2005), o Estado de São Paulo insere-se entre os grandes produtores de bens minerais do país. Especificamente quanto aos bens minerais de uso na construção civil, destacam-se as matérias-primas in natura, como areia, brita e rochas ornamentais, argilas para cerâmica vermelha e rochas carbonáticas para a fabricação de cimento e cal.

No Estado de São Paulo são destacados alguns polos minerários de areia, sendo: a Grande São Paulo, o Vale do Paraíba, a região do Médio Tietê, o Vale do Ribeira e adjacências, a região de Campinas, Ribeirão Preto e a região de Bauru e Botucatu.

Nesse sentido, de acordo com informações disponíveis no site ${ }^{1}$ da Assembleia Legislativa do Estado de São Paulo, a atividade areeira atualmente tem grande importância econômica para a Região do Vale do Paraíba. No ano de 2006, esta correspondia por cerca de $5 \%$ da produção nacional e $25 \%$ do Estado, com projeções de que $80 \%$ da produção era destinada à Capital de São Paulo (SÃO PAULO, 2006).

De acordo com Ribeiro (2010), a extração de areia, na várzea do rio Paraíba do Sul, destina-se à construção civil e, entre os anos de 2006 e 2010, houve um aumento na produção nacional, dobrando o percentual supracitado.

1 Site: http://www.al.sp.gov.br/noticia/?id=286080 
Segundo o Instituto de Pesquisas Tecnológicas - IPT (2015), o Vale do Paraíba conta com uma produção diversificada de minerais e rochas industriais, mas tem seu grande destaque para a mineração de areia, cuja produção, iniciada em meados da década de 1940 diante à escassez da exploração de areia nos rios Tietê e Pinheiros, extrapola o abastecimento dos centros consumidores locais e vem contribuindo, de forma crescente, sobretudo para o suprimento da indústria da construção civil na Região Metropolitana de São Paulo - RMSP.

Os dados levantados pelo IPT permitiram observar que, no ano de 2013, o município de Jacareí se apresentou como o maior produtor de areia no Vale do Paraíba e São José dos Campos como o maior consumidor.

Entendendo as disparidades da atuação minerária e da gestão dos municípios em estudo, pode-se compará-los e analisar o conflito ambiental existente, identificando suas problemáticas em relação ao planejamento urbano e regional.

O município de Jacareí, o maior produtor de areia da atualidade na Região do Vale do Paraíba e Litoral Norte, corre o risco de, também, vir a sofrer ainda mais com a intensa exploração desse minério, pois, sem fiscalização e uma falta de legislação unitária para a causa, contribui para exaurir os recursos existentes e, consequentemente, o desgaste do meio ambiente local.

Para amenizar o impacto ambiental em municípios tão próximos ou até mesmo pertencentes a uma mesma Região Metropolitana, como ocorre em Jacareí e São José dos Campos, a existência de uma legislação minerária comum a todos os municípios poderia evitar muitos problemas ambientais.

\section{METODOLOGIA}

Nota-se que, com o crescimento das cidades, o espaço urbano vem se transformando com a necessidade da população.

De acordo com Santos (1985, p. 5):

O espaço deve ser considerado como uma totalidade, a exemplo da própria sociedade que the dá vida. O espaço, como uma realidade é uno e total. É por isso que a sociedade como um todo atribui, a cada um dos seus movimentos, um valor diferente a cada fração do território e que cada ponto do espaço é solidário aos demais, em todos os momentos.

A extração de areia é decorrente disso, com a busca de materiais para a construção civil e com o crescimento urbano, e populacional, a demanda por esse material cresce, constantemente, para suprir as necessidades do mundo moderno. 
Considerando a localização estratégica dos municípios estudados e o crescimento econômico e populacional dos municípios de Jacareí e São José dos Campos, nota-se, a partir de então, a importância de uma preocupação na dinâmica das cidades, seu crescimento urbano diante de seus conflitos ambientais.

Portanto, o espaço é caracterizado pelas construções físicas e pelas relações sociais que interagem e habitam-no. A sociedade produz o seu espaço.

Segundo Silva (2009 p. 55):

\begin{abstract}
Desse modo, o espaço além de instância social, que tende a reproduzir-se, tem uma estrutura que corresponde à organização feita pelo homem. É uma instância, subordinada à lei da totalidade, que dispõe de certa autonomia e se manifesta por meio de leis específicas de sua evolução. Assim, o espaço organizado é também uma forma, resultado da interação de variáveis. O espaço social corresponde ao espaço humano, lugar de vida e trabalho, morada do homem, não possuindo definições fixas definitivas.
\end{abstract}

De acordo com Hough (1998), a forma urbana é resultado de um constante e dinâmico processo evolutivo, determinado tanto pelos processos naturais, quanto pelos humanos, com suas forças econômicas, políticas, demográficas e sociais.

Santos (1979, p.10) lembra que:

O espaço reproduz a totalidade através das transformações determinadas pela sociedade, modos de produção, distribuição da população, entre outras necessidades, desempenham funções evolutivas na formação econômica e social, influencia na sua construção e também é influenciado nas demais estruturas de modo que toma um componente fundamental da totalidade social e de seus movimentos.

Segundo o Instituto de Pesquisas Tecnológicas (2015), nas últimas décadas a economia paulista sofreu um importante processo de interiorização, do qual resultaram novos polos de desenvolvimento regional, ocorrendo, assim, uma demanda crescente por insumos, principalmente por recursos minerais.

A Região do Vale do Paraíba é uma área expressiva na atividade de mineração, principalmente por causa das reservas de areia de importante utilização na construção civil. Como se pode notar na Figura 1, o eixo do Vale do Paraíba, onde temos o Rio Paraíba do Sul e diversos outros municípios estudados, é marcado pela intensa produção de areia.

Nota-se, a partir da Figura 1, uma grande presença de explorações de areia ao longo do eixo de todo o Vale do Paraíba.

Porém, esse território, também, tem outros fatores importantes que competem com a mineração, tais como: a expansão urbana e industrial, o adensamento da ocupação agrícola e a demanda cada vez maior por recursos hídricos. Essa disputa dos recursos naturais e território conduzem à interposição de instrumentos de ordenamento 
territorial que possibilitem garantir os recursos naturais, as atividades de mineração e outras formas de uso do solo, sem que haja comprometimento da qualidade ambiental (INSTITUTO..., 2015).

Segundo Villaça (1998), o espaço e a organização política do espaço expressam relações sociais, mas, ao mesmo tempo, reagem sobre elas.

Diante disso, pode-se dizer que a sociedade tem que opinar em relação ao espaço em que vive, pois é essa sociedade que é a maior interessada e atingida nesses processos de intervenções.

\section{Figura 1. Mancha urbana e mineração de agregados à leste do Estado de São} Paulo.

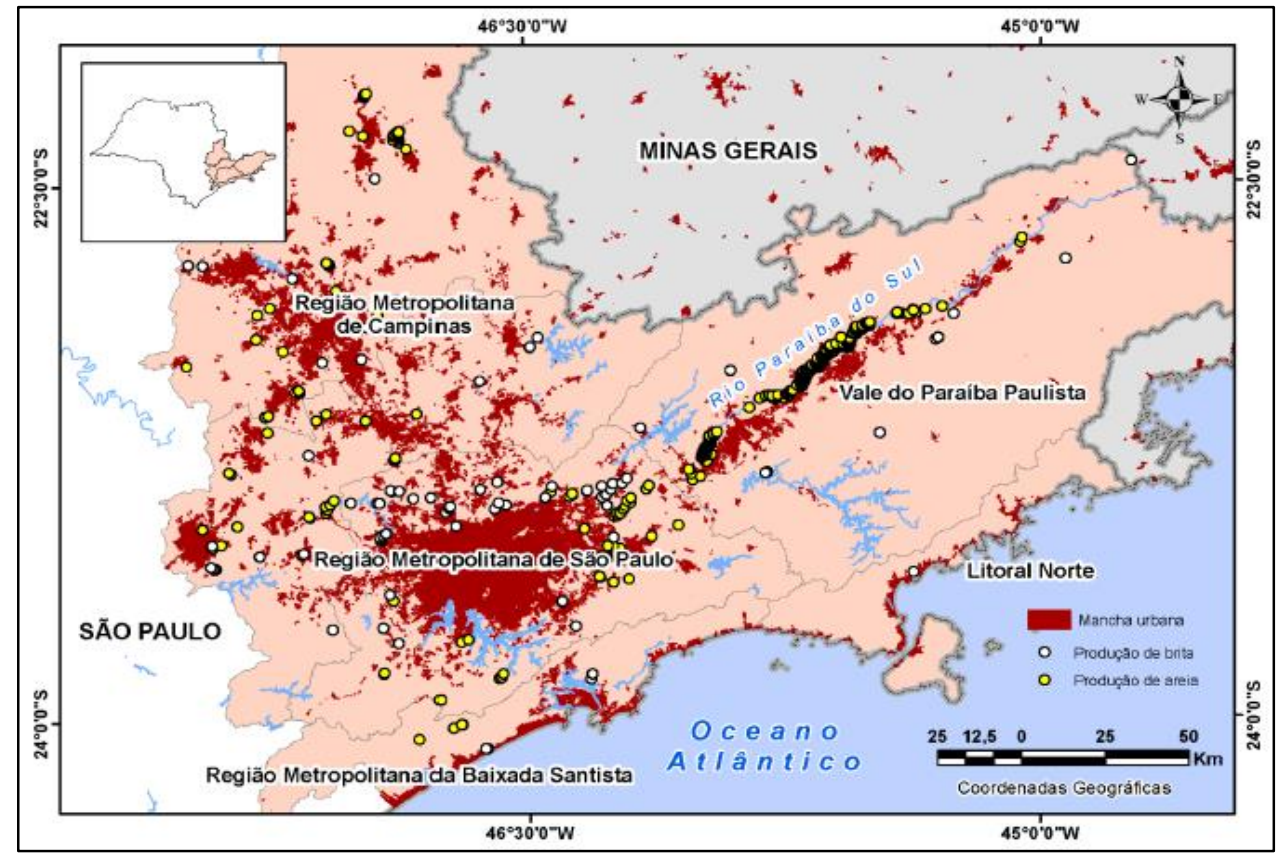

Fonte: Fantin (2011).

\section{A DEMANDA DE AREIA}

Segundo Ribeiro (2010), São Paulo é o estado com maior produção, concentrando, em 2013, 23\% do total nacional, mesma porcentagem dos anos anteriores, porém menor do que a que detinha em 2006, que era de $27 \%$.

Os principais locais de extração de areia no Estado de São Paulo são: a região do Vale Paraíba, os municípios de Sorocaba e Piracicaba e a região do Vale do Ribeira (BRASIL, 2009).

Segundo o relatório de Ordenamento Territorial Geomineiro (OTGM ${ }^{1}$ ), do IPT (INSTITUTO..., 2015), apenas os municípios de São José dos Campos e Lavrinhas não

\footnotetext{
1 OTGM é um instrumento que deve ser integrado ao ZEE - Zoneamento Ecológico Econômico e incorporado nos Planos Diretores Municipais, de modo a inserir a mineração de maneira sustentável no planejamento municipal e regional. (IPT, 2015).
} 
possuem mineração de areia, já os demais municípios são produtores, sendo que em seis deles a extração ultrapassa o montante anual de 1 milhão de toneladas (Figura 2).

Conforme a Figura 2, pode-se avaliar a distribuição da produção e do consumo de areia por município. A maior produção é do município de Jacareí, com 3,4 milhões de toneladas de areia extraída ao ano.

\section{Figura 2. Produção e consumo de areia nos municípios abrangidos pelo Ordenamento Territorial Geomineiro do Vale do Paraíba em 2013.}

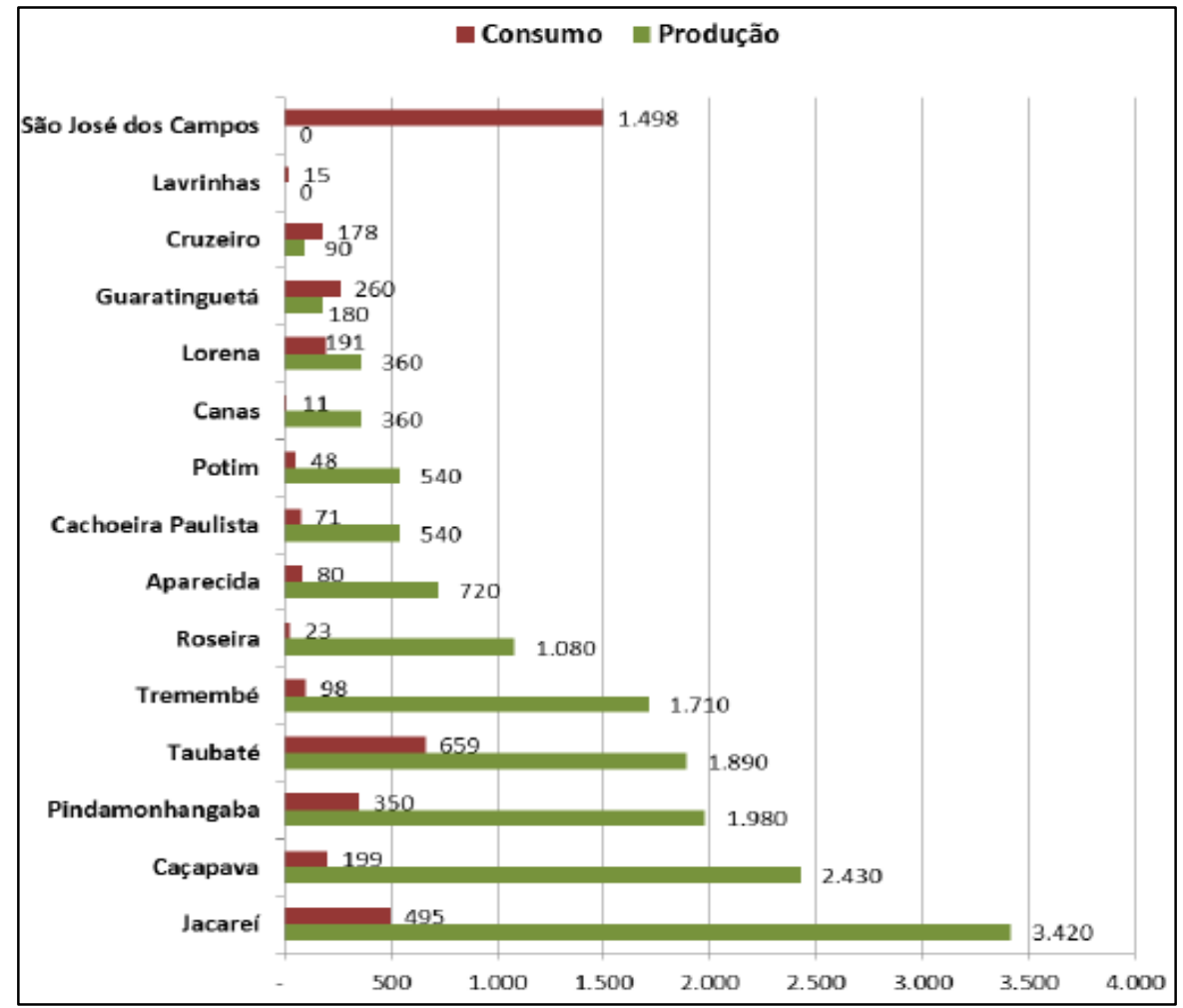

Fonte: Instituto..., (2015)

Sobre os municípios estudados, por meio do Ordenamento Territorial Geomineiro no Vale do Paraíba, verificou-se que Jacareí produz, anualmente, 3.420 .000 toneladas de areia e com sua população de 224.826 habitantes (INSTITUTO..., 2014) consome 494.617 toneladas/ano da areia produzida em suas terras. O restante exporta para outros municípios e regiões do estado de São Paulo. Já São José dos Campos não produz areia, mas, com sua população de 681.086 habitantes (INSTITUTO..., 2014), consome 1.498.389 toneladas/ano, devendo, assim, importar toda essa quantidade de outros municípios que produzem areia.

Portanto, identifica-se a disparidade que ocorre na produção e consumo de areia entre Jacareí e São José dos Campos, mostrando que São José dos Campos é o município de maior população do Vale do Paraíba, com o Produto Interno Bruto - PIB de $\mathrm{R} \$ 22.018 .043$, correspondendo a $76,04 \%$ da Sub-Região 1, levantamento no ano de 2009, segundo EMPLASA (2012). São José dos Campos é o município que mais 
consome areia, porém não a produz, necessitando, assim, de importar toda a areia para o seu consumo.

No entanto, Jacareí, que tem a maior produção de areia da RMVPLN, sua população consome, aproximadamente, $14 \%$ do que produz, portanto, produz mais areia do que consome e grande parte desse mineral produzido é exportado, às vezes para municípios vizinhos, mas grande parte dessa areia vai atender a demanda de outras regiões metropolitanas. Segundo EMPLASA (2012), o PIB de Jacareí totalizou, em 2009, R $\$ 4.832 .375$, correspondendo $16,03 \%$ da Sub-Região 1.

Considerando os 15 municípios abrangidos no Ordenamento Territorial Geomineiro do Vale do Paraíba, a produção anual situa-se, atualmente, em cerca de 15,3 milhões de toneladas/ano, de acordo com a Tabela 1.

Tabela 1. Mineração de areia nos 15 municípios inclusos no Ordenamento Territorial Geomineiro do Vale do Paraíba /base 2013.

\begin{tabular}{|c|c|c|c|c|c|}
\hline $\begin{array}{c}\text { Municipios do OTGM } \\
\text { Vale do Paraíba }\end{array}$ & $\begin{array}{l}\text { Produção } \\
\text { Estimada } \\
\text { Anual }(t) \\
\end{array}$ & $\begin{array}{l}\text { População } \\
\text { (IBGE/2014) }\end{array}$ & $\begin{array}{l}\text { Consumo } \\
\text { Estimado } \\
\text { Anual (t) } \\
\end{array}$ & $\begin{array}{c}\text { Município } \\
\text { Exportador de } \\
\text { Areia } \\
\end{array}$ & $\begin{array}{c}\text { Município } \\
\text { Importador de } \\
\text { Areia }\end{array}$ \\
\hline Aparecida & 720.000 & 36.184 & 79.605 & 640.395 & \\
\hline Caçapava & 2.430 .000 & 90.426 & 198.937 & 2.231 .063 & \\
\hline Cachoeira Paulista & 540.000 & 32.046 & 70.501 & 469.499 & \\
\hline Canas & 360.000 & 4.788 & 10.534 & 349.466 & \\
\hline Cruzeiro & 90.000 & 80.749 & 177.648 & & 87.648 \\
\hline Guaratinguetá & 180.000 & 118.378 & 260.432 & & 80.432 \\
\hline Jacareí & 3.420 .000 & 224.826 & 494.617 & 2.925 .383 & \\
\hline Lavrinhas & - & 7.002 & 15.404 & & 15.404 \\
\hline Lorena & 360.000 & 86.764 & 190.881 & 169.119 & \\
\hline Pindamonhangaba & 1.980 .000 & 158.864 & 349.501 & 1.630 .499 & \\
\hline Potim & 540.000 & 21.984 & 48.365 & 491.635 & \\
\hline Roseira & 1.080 .000 & 10.257 & 22.565 & 1.057 .435 & \\
\hline São José dos Campos & - & 681.086 & 1.498 .389 & & 1.498 .389 \\
\hline Taubaté & 1.890 .000 & 299.423 & 658.731 & 1.231.269 & \\
\hline Tremembé & 1.710 .000 & 44.399 & 97.678 & 1.612 .322 & \\
\hline TOTAL & 15.300 .000 & 1.897 .176 & 4.173.788 & & \\
\hline
\end{tabular}

Fonte: Adaptado de Instituto... (2015).

Diante desses dados, são nítidas as disparidades que ocorrem na produção e consumo de areia entre alguns municípios da Sub-Região 1 da RMVPLN, principalmente entre os municípios de Jacareí e São José dos Campos, como pode ser visto na Figura 3.

Por intermédio da Figura 3, pode-se verificar a demanda e produção dos municípios estudados, onde Jacareí produz, em média, 3.420.000 toneladas/ano de areia, sendo que São José dos Campos não produz areia em seu município.

Jacareí consome em torno de $14 \%$ do que produz, enquanto exporta o resto de sua produção. 
Em comparação, São José dos Campos, por não produzir nada, tem que importar tudo o que consome, aproximadamente, 1.498.389 toneladas/ano de areia.

Figura 3. Relação da produção e consumo VS importação e exportação de areia

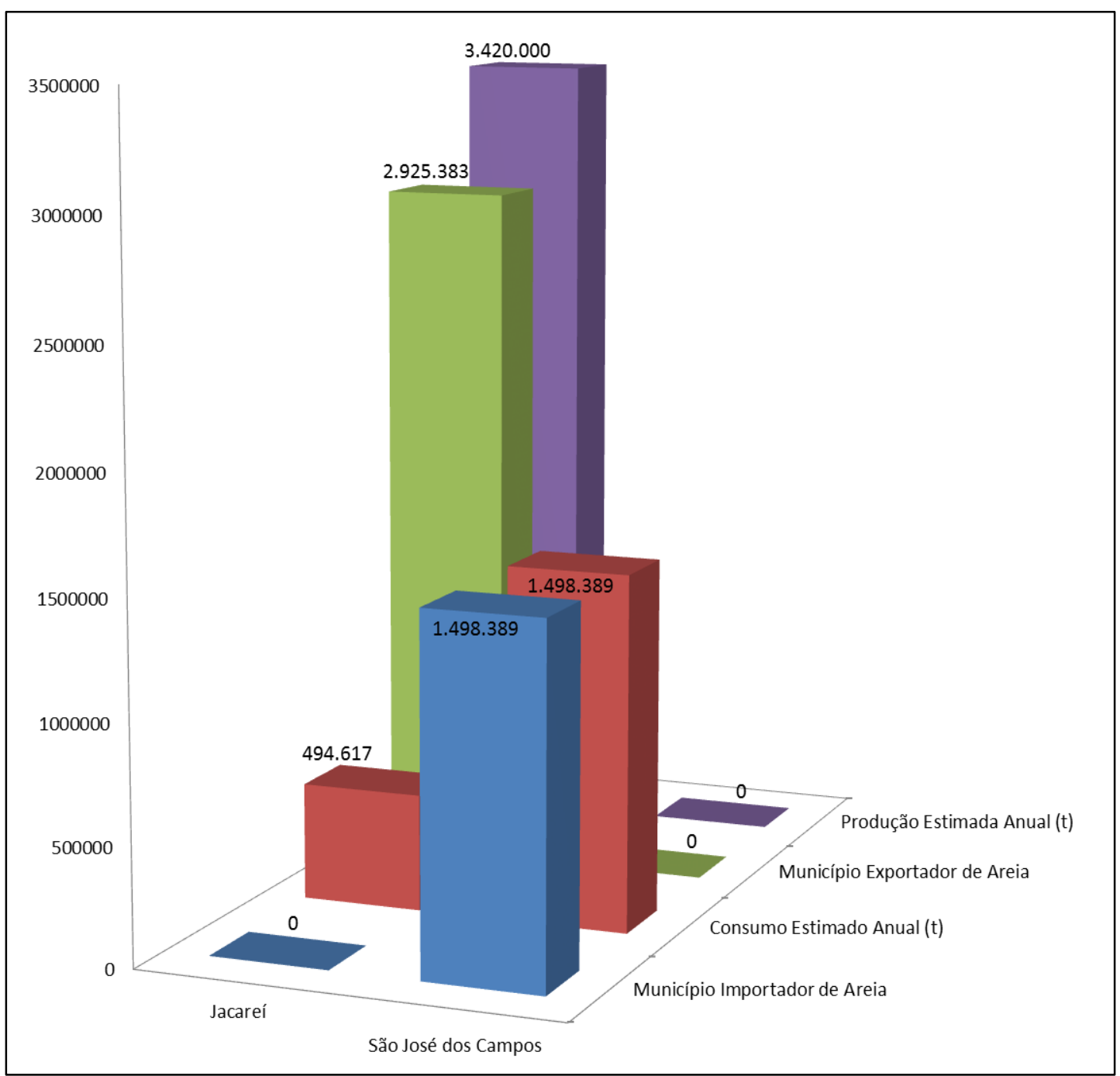

Fonte: Adaptado de Instituto... (2015).

\section{ANÁLISE DOS DADOS REFERENTES AOS MUNICÍPIOS ESTUDADOS}

A escolha pelo recorte dos municípios de Jacareí e São José dos Campos se dá, primeiramente por terem uma gestão bem distinta, no tocante à extração de areia, mesmo diante da proximidade de seus municípios, e por serem os municípios de maior produção e maior consumo de areia da RMVPLN, respectivamente.

A Figura 4 representa o recorte da imagem orbital colorida em escala ampliada, onde se observa que próximo da calha do Rio Paraíba do Sul até o limite municipal com São José dos Campos é possível visualizar a diversidade das cavas de areia (cores claras e distintos tons de verde e azuladas), as quais estão associadas com a diversidade de exploração. Ainda, na Figura 4, pode-se constatar que, na calha do rio Paraíba do Sul no município de São José dos Campos, grande parte do eixo do rio é 
circundado por vegetação densa, ora mais rasteira, bem como a presença de lagoas em tons escuros que representam as cavas abandonadas.

Figura 4. Recorte da imagem orbital com destaque das áreas de exploração de areia nos municípios de Jacareí e São José dos Campos.

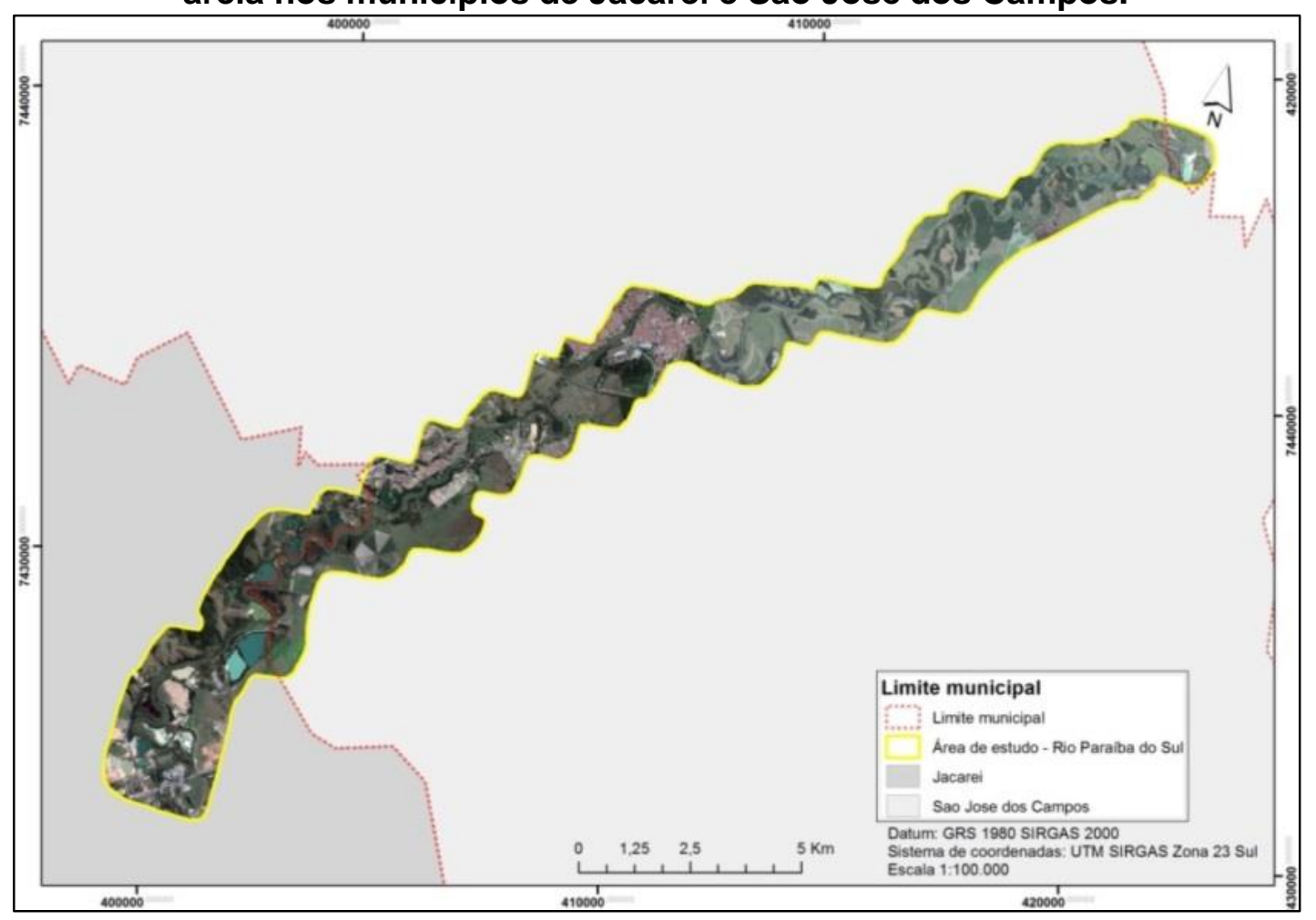

Fonte: Adaptado de Google Earth (2015).

Na Figura 4, nota-se, também, que a esquerda da linha vermelha pontilhada situase parte do município de Jacareí, onde se podem visualizar as cavas provenientes da exploração de areia formando as lagoas, que se apresentam nas cores rósea claro, verde claro e escuro, ao longo do eixo do rio Paraíba do Sul.

Já, à direita da linha vermelha pontilhada situa-se parte do município de São José dos Campos, onde se pode ver, por intermédio da imagem, que grande parte do eixo do Rio Paraíba do Sul é circundado por vegetação densa, ora rasteira, porém não nota-se a presença de cavas provenientes da exploração de areia.

Em comparação, por meio da imagem orbital, onde aparecem esses dois municípios, nota-se que Jacareí é tomada pela extração de areia, pois, visualmente, percebem-se as lagoas e áreas desmatadas.

Portanto, por intermédio de uma mesma imagem orbital dos dois municípios, pode-se dizer que há uma grande diferença no aspecto visual entre eles, mostrando que a área territorial de Jacareí se caracteriza bem mais degradada, por causa da exploração de areia, do que a de São José dos Campos.

Analisando a proximidade dos municípios de Jacareí e São José dos Campos e a forma que tratam essa temática de modo tão diferenciado, nota-se a peculiaridade em 
como cada município trata seu planejamento urbano e faz a gestão minerária de suas terras, sendo que ambos estão inseridos numa mesma (Sub-Região da) Região Metropolitana do Vale do Paraíba e Litoral Norte - RMVPLN.

De acordo com a Figura 5, pode-se identificar o número e a dimensão de cavas ativas e desativadas no município de Jacareí e como elas se dispõem ao longo do eixo do Rio Paraíba do Sul, sendo este o maior produtor de areia da Região do Vale do Paraíba.

Figura 5. Classificação das cavas de areia no município de Jacareí - ano 2008.

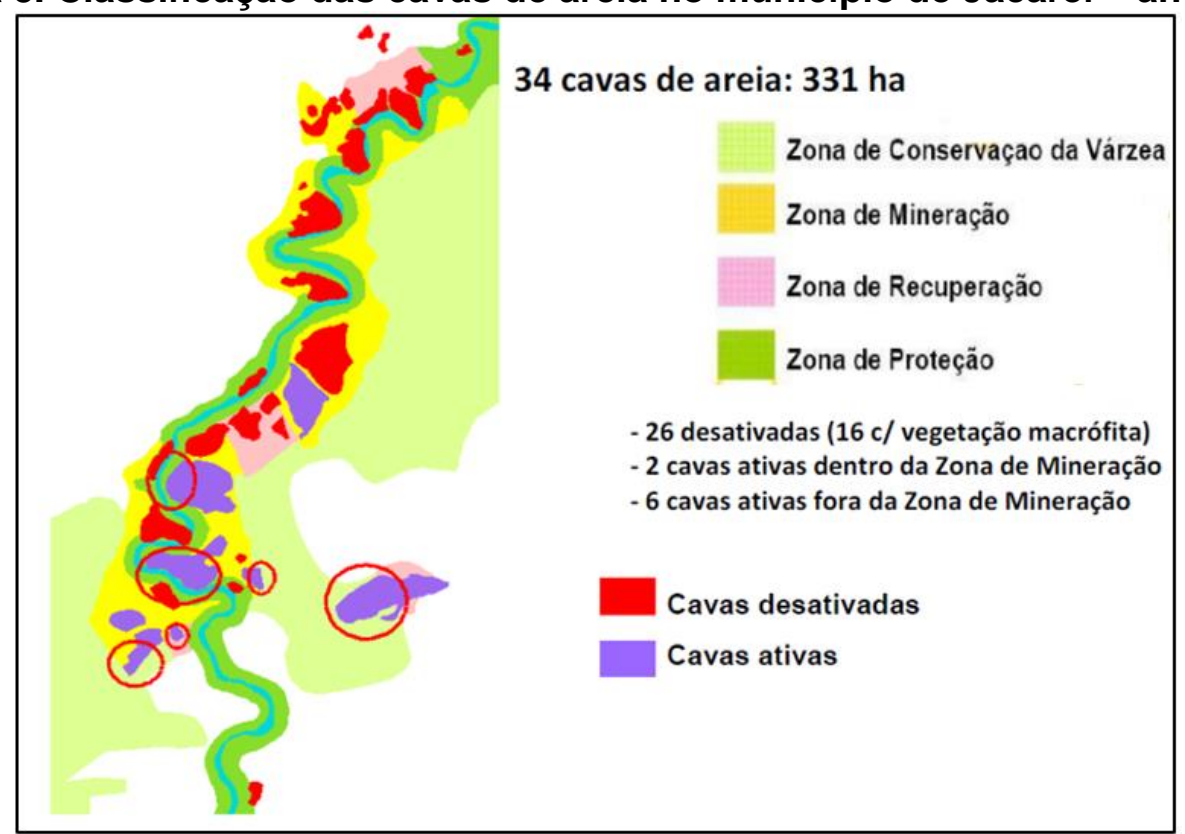

Fonte: São Paulo (2008).

Segundo o relatório do MP/SP (SÃO PAULO, 2008), no ano de 2008 o município de Jacareí contava com 34 cavas de areia, totalizando 331 hectares de área de cavas.

Dessas 34 cavas de areia, 26 estavam desativadas, 2 encontravam-se ativas dentro da zona de mineração e outras 6 ativas também, porém, fora da zona de mineração.

A Figura 6 mostra o crescimento das áreas das cavas de areia no município de Jacareí.

Figura 6. Área (ha) das cavas de areia de 1986 à 2008 em Jacareí.

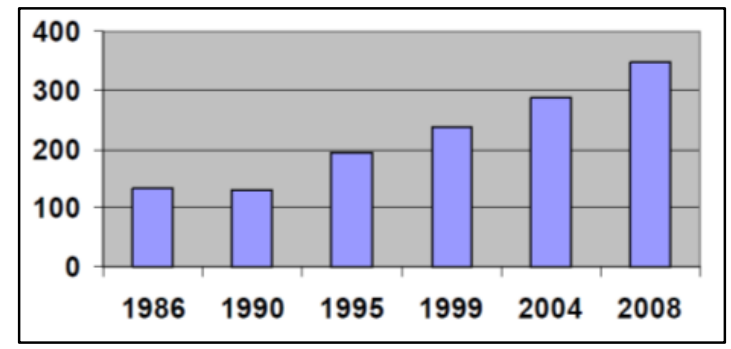

Fonte: São Paulo (2008). 
Pela Figura 6, constata-se que as áreas de exploração de areia no município cresceu mais que o dobro entre o período de 1990 a 2008, o que acarretou em mais áreas a serem fiscalizadas, para controle da mineração e medidas de recuperação ambiental.

$\mathrm{Na}$ Figura 7, identifica-se a quantidade de cavas de areia no município de São José dos Campos e como se dispõem ao longo do eixo do Rio Paraíba do Sul.

Figura 7. Classificação das cavas de areia em São José dos Campos - 2008.

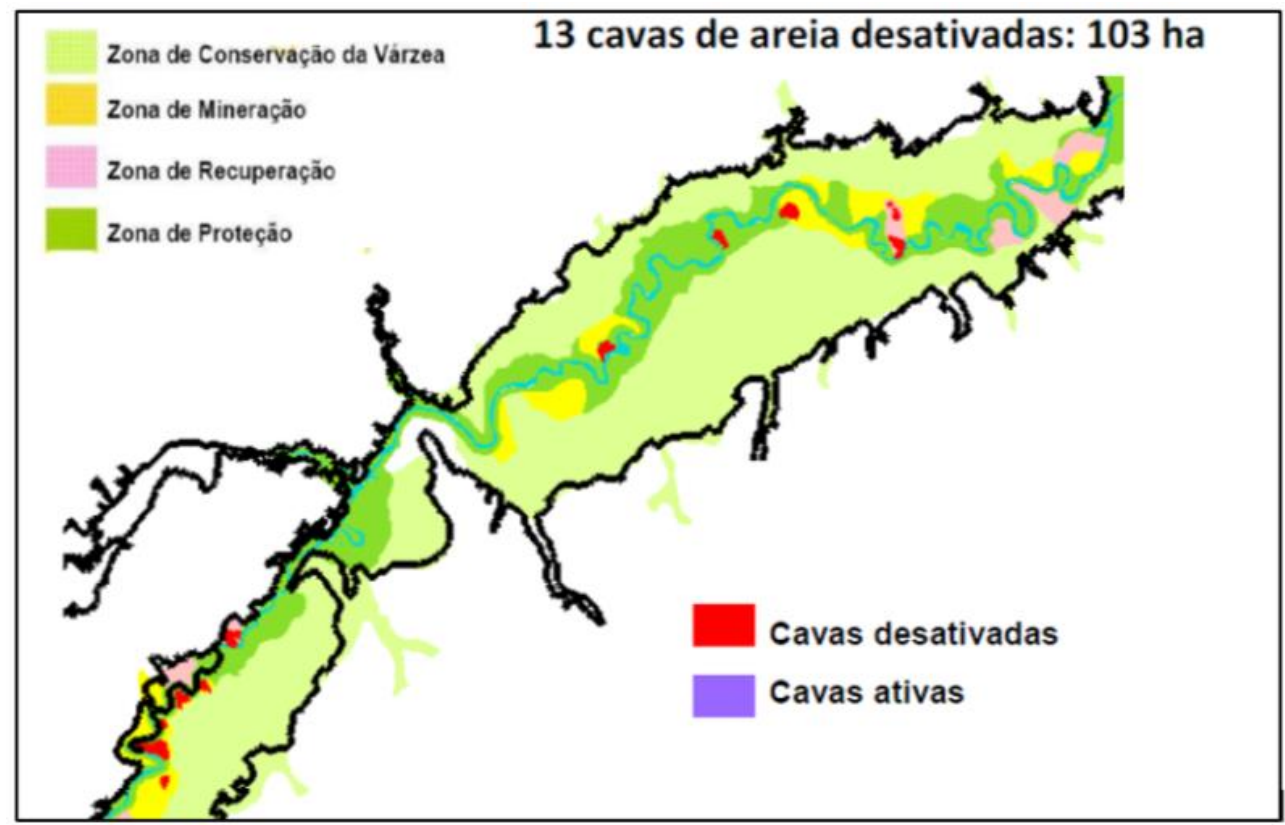

Fonte: São Paulo (2008).

Nota-se, pela Figura 7, que, no ano de 2008, já não havia mais nenhuma cava de areia ativa no município, mas este contava com 13 cavas de areia desativadas, totalizando uma área de 103 hectares.

Figura 8. Área (ha) das cavas de areia de 1986 a 2008 em São José dos Campos

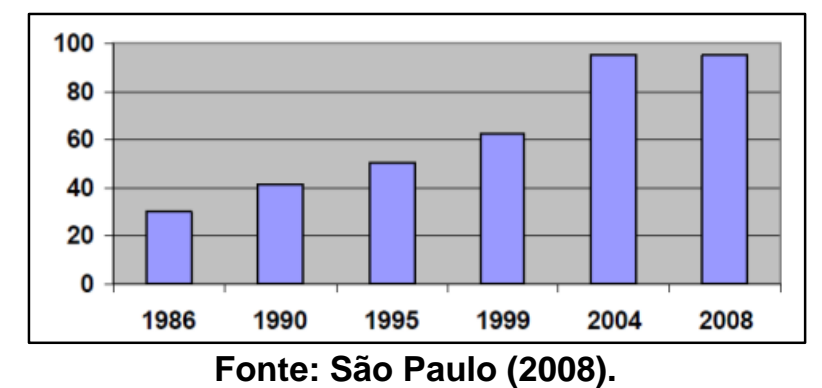

Pela Figura 8, verifica-se que o crescimento das áreas das cavas de areia no município de São José dos Campos se deu até o ano de 2004, quando estagnou-se, conforme levantamento de 2008. 
Lembrando que, a partir de 1990 a extração de areia já havia sido proibida pela Lei Orgânica do município; e, segundo São Paulo (2008), a exploração de areia continuou, clandestinamente, nos 15 anos subsequentes à lei. Essa afirmativa é comprovada pelo Gráfico 4 que mostra o aumento das áreas das cavas de areia de 1990 à 2004, mesmo sendo esse período após a proibição da extração de areia em São José dos Campos.

Se a legislação fosse cumprida na íntegra e a fiscalização fosse realmente eficaz, não haveria exploração ocorrendo fora da Zona de Mineração, conforme visto na Figura 5 e, também, explorações clandestinas atuando nos municípios da região do Vale do Paraíba, conforme identificado na Figura 8. Com isso, teria uma situação ambiental e político/econômica muito mais favorável ao desenvolvimento da RMVPLN.

O Ministério Público, em seu levantamento, identifica que, das 311 cavas de extração de areia no Vale do Paraíba, 230 estão inativas, totalizando uma área corresponde a 1.800 campos de futebol. Dessas 81 cavas ativas, só 22 não apresentam irregularidades quanto ao espaço oficialmente definido para a atividade (ALVES, 2017).

O impacto gerado no meio ambiente pela extração de areia é muitas vezes irreversível, conforme ilustrado pela Figura9.

Figura 9. Lagoas formadas pela extração de areia no município de Jacareí

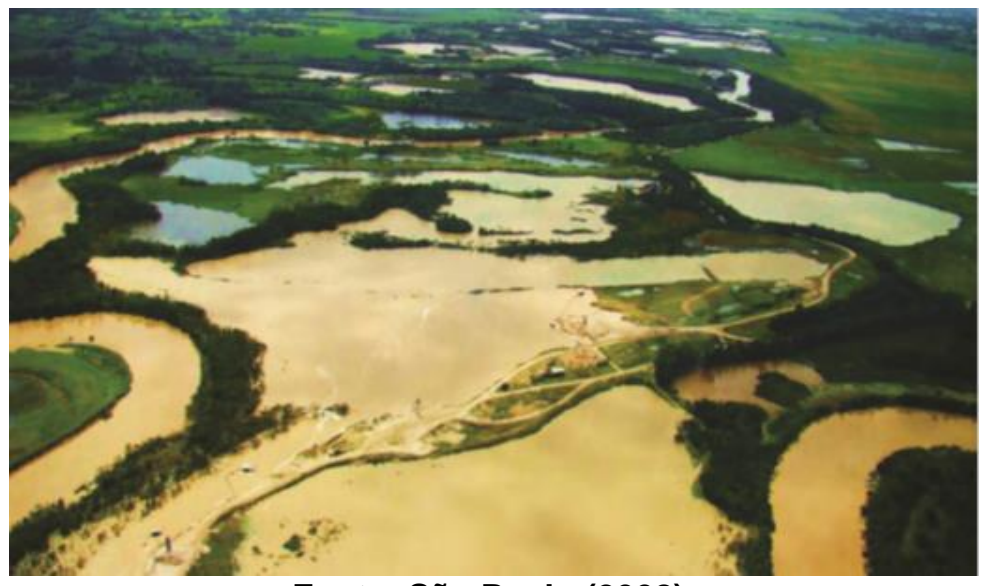

Fonte: São Paulo (2008).

Conselho... (2014) lembra que é necessário coibir a ilegalidade, a clandestinidade e prestigiar a mineração que respeita o meio ambiente por intermédio das melhores práticas de planejamento mineiro.

A ocupação urbana e a extração mineral se dá, principalmente, junto ao mercado imobiliário local e a um desenvolvimento perverso que vem aumentando e pode se tornar incontrolável se não houver uma gestão que minimize essa problemática e crie um desenvolvimento sustentável (FANTIN, 2005).

Diante dessas problemáticas, em 2013 foi instituída a Câmara Temática de Mineração, com o objetivo de promover o debate sobre o ordenamento territorial da 
mineração, com propostas de soluções para a atividade e o desenvolvimento sustentável da RMVPLN.

Com isso, a Subsecretaria de Mineração vem realizando o Ordenamento Territorial Geomineiro - OTGM, que é um instrumento de planejamento da atividade mineral de uma região integrando às diretrizes de Governo, aos anseios da sociedade e aos processos de desenvolvimentos sustentáveis de determinada região. O OTGM tem por objetivo fornecer subsídios técnicos para o planejamento do uso e ocupação do solo municipal, atualização e fortalecendo os Planos Diretores Municipais.

Acredita-se que, a partir desse Ordenamento Territorial Geomineiro do Vale do Paraíba, por ser um instrumento de abrangência regional, tais discrepâncias abordadas nas gestões minerárias entre os municípios estudados serão minimizadas e a produção e consumo da areia, na região, serão mais racionais e monitoradas.

Alves (2017) relata que o presidente do Instituto Eco-Solidário, Jeferson Rocha, acredita que o mais importante é definir um novo zoneamento minerário para o todo 0 Vale do Paraíba, atualmente em estudo pelo governo estadual, pois se for considerado somente o zoneamento existente, ele só existe entre as áreas dos municípios de Jacareí e Pindamonhangaba e como essa área já está esgotada, os mineradores estão indo além desses municípios, onde não há um zoneamento para a mineração, colocando, então, o Rio Paraíba do Sul em risco.

Para garantir uma gestão mais eficaz e atuante, deve haver uma maior participação popular junto aos movimentos ambientalistas, como o que ocorreu em São José dos Campos, para o impedimento das atividades minerárias em suas terras, assim é possível cobrar mais ação da política pública, para a minimização desses impactos gerados por intermédio da exploração mineral.

Pela análise das informações obtidas, constatou-se a importância de se ter uma legislação integradora, visando ao desenvolvimento da região metropolitana como um todo.

Atuando de forma igualitária para toda a Região Metropolitana do Vale do Paraíba, verifica-se que é possível sanar os problemas pontuais, principalmente esses que afetam a questão ambiental de forma tão distinta entre municípios vizinhos.

Com o suporte do planejamento urbano e regional de forma efetiva, diagnosticado por meio de estudos e propostas de intervenções que organizem espacialmente as atividades e regulem de maneira coerente, pode-se, assim, identificar a problemática atual e propor possíveis soluções, tanto para mitigar os impactos diagnosticados (Figura 10), quanto para melhorar o desenvolvimento econômico e socioambiental dos municípios. 
Pelo exposto, verifica-se que os municípios em análise, localizados na mesma Região Metropolitana, com as mesmas legislações nos âmbitos federal e estadual atuam de maneira bem distinta na gestão minerária de seus territórios.

Na verdade, o objetivo não é impedir a exploração de areia para não haver mais degradação ambiental, mas sim, fazê-la segundo os princípios legais das legislações vigentes, mantendo um equilíbrio na extração de areia entre os municípios. Não adianta um município não extrair areia nas suas terras com a proposta de ser ambientalmente e legalmente correto, se este importa toda a areia de que necessita dos municípios vizinhos e, consequentemente, torna-se extremamente agressivo ao meio ambiente, para suprir suas necessidades. No final, a região toda é prejudicada.

Figura 10. Foto da extração de areia no município de Jacareí.

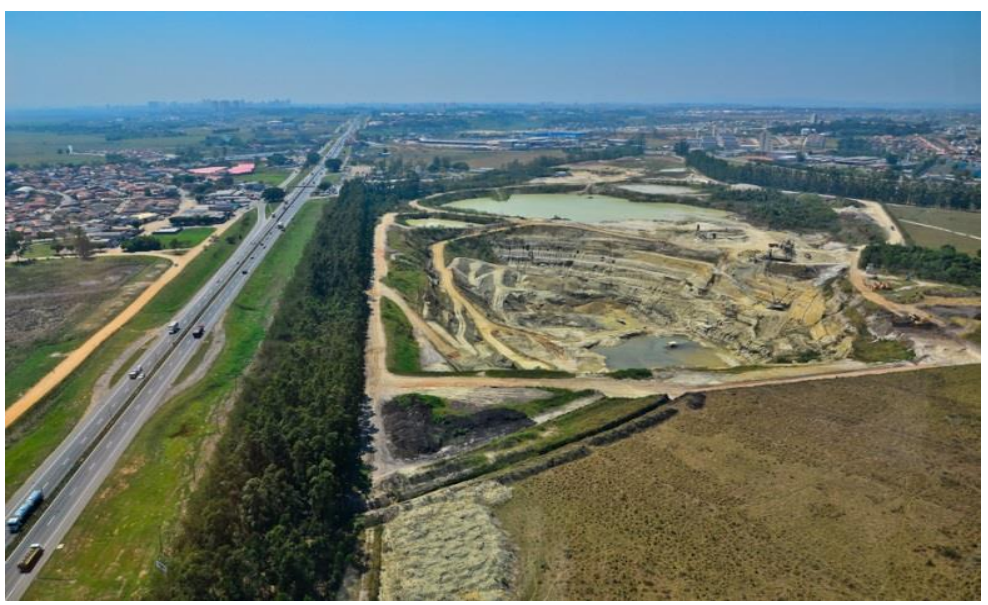

Fonte: Leon (2013).

\section{CONSIDERAÇÕES FINAIS}

O grande impasse diagnosticado ao longo deste levantamento é a problemática existente na relação entre a demanda do homem moderno e o equilíbrio ambiental, neste caso mais especificamente a relação entre a demanda de areia e sua produção nos municípios estudados.

A exploração de areia ao longo do Vale do Paraíba se tornou muito importante para o desenvolvimento urbano a partir da industrialização local e do crescimento das cidades, porém, junto a esse desenvolvimento, veio, também, a responsabilidade diante das alterações no entorno do Rio Paraíba do Sul, gerando os conflitos socioeconômicos-ambientais.

O grande desafio do planejamento urbano é tentar solucionar esse problema, tornando-se uma ferramenta eficaz no desenvolvimento do espaço e nas relações sociais.

Sobre os municípios estudados, nota-se a disparidade na gestão minerária de municípios que fazem limite entre si, pois, enquanto Jacareí produz mais do que consome e comercializa o que sobra, São José dos Campos tem que comprar toda a 
areia para a sua demanda, uma vez que não extrai areia em suas terras. Diante disso, pode-se dizer que São José dos Campos explora, passivamente, a areia de outros municípios, não degradando suas terras, porém é conivente na degradação da terra do município vizinho.

A diferença na gestão minerária nos municípios de Jacareí e São José dos Campos se dá, principalmente, por causa dos atores envolvidos, onde, em São José dos Campos houve um grande movimento contra a exploração de areia no seu território, algo que não ocorreu em Jacareí, mesmo pertencendo à mesma Região Metropolitana.

O município de Jacareí, o maior produtor de areia da RMVPLN, pode correr o risco de esgotar o minério em suas terras, por causa da intensa exploração, sem uma fiscalização adequada que contribui na degradação do meio ambiente.

Os municípios, de modo geral, dispõem de vários instrumentos legais de planejamento e gestão de seu território, seguindo as legislações: Federal e Estadual e, assim sendo, podem implantar uma política municipal/regional de gerir os recursos minerais dos territórios em questão, mas, além das legislações, deve-se existir um diálogo em conjunto entre a União, Estado, Municípios, Iniciativa Privada, Sociedade Civil e Ministério Público, visando a uma melhor fiscalização dessas explorações, garantindo que a legislação seja cumprida, acompanhando e controlando a exploração, além da mitigação dos impactos já causados pela atividade minerária.

Para uma melhor gestão e aplicabilidade da lei, a conscientização sobre os conflitos ambientais deve atingir a população, para que esta se torne cada vez mais participativa, pois é a mais prejudicada nesse processo.

Com base nas informações obtidas sobre a extração de areia nos municípios de Jacareí e São José dos Campos, verifica-se que a grande problemática é de se fazer cumprir a lei e não deixar que os interesses particulares corrompam o ideal, em busca de um melhor desenvolvimento para a região.

Os municípios estudados têm sua legislação local distinta, porém pertencem a uma mesma região metropolitana, diante disso, analisa-se que o estatuto da metrópole pensa em política, mas não abrange tudo que deveria ser abordado, pois não questiona tais relações entre a exploração mineral, o território urbano e o meio ambiente.

A degradação decorrente da exploração de areia não deve ser vista de modo individual, mas sim em relação ao todo e, por isso, tratando-se de uma Região Metropolitana, deveria haver uma legislação que fosse integradora, portanto, se os municípios da RMVPLN tivessem uma lei de zoneamento minerário da metrópole, na qual houvesse a identificação do potencial minerário ao longo da região metropolitana, compatibilizando com as atividades rurais e urbanas e que unificasse a ação da política minerária e a fiscalização, os impactos oriundos da exploração de areia na região poderiam ser minimizados. 


\section{REFERÊNCIAS}

ALVES, X. Sete em cada 10 cavas do Paraíba estão irregulares. Jornal eletrônico 0 Vale, 2017. Disponível em: <http://www2.ovale.com.br/sete-em-cada-10-cavas-doparaiba-est-o-irregulares-1.743839>. Acesso em: 7 out. 2017.

BRASIL. Ministério de Minas e Energia. A Mineração Brasileira: Relatório Técnico 51. Brasília, 2009. Disponível em:

<http://www.mme.gov.br/documents/1138775/1256650/P28_RT51_Perfil_da_Mica.pdf/ 1a2f869d-56ec-4c2d-95ca-f8635a5fa75e>. Acesso em: 10 jun. 2015.

CONSELHO DE DESENVOLVIMENTO DA REGIÃO METROPOLITANA DO VALE DO PARAÍBA E LITORAL NORTE. Câmara Temática de Mineração. Relatório de Atividades, 2014.

EMPLASA - Empresa Paulista de Planejamento Metropolitano S.A. Região Metropolitana do Vale do Paraíba Litoral Norte. São Paulo: EMPLASA, 2012.

FANTIN, M. Contribuição para a formulação de políticas públicas de desenvolvimento sustentável e gestão do meio ambiente em Áreas de Proteção Ambiental: um estudo de caso da várzea do rio Paraíba do Sul no Município de São José dos Campos-SP. 290f. Dissertação (Mestrado em Planejamento Urbano) Universidade do Vale do Paraíba. São José dos Campos, 2005.

FANTIN, M. Gestão de agregados minerais: análise e subsídios para políticas públicas. 2011. 519f. Tese (Doutorado) - Universidade Estadual de Campinas, Campinas, 2011.

GOOGLE EARTH. Imagem Orbital com destaque das áreas de exploração de areia nos municípios de Jacareí e São José dos Campos. 2015. Disponível em: <https://www.google.com/earth/>. Acesso em: 15 fev. 2016.

HOUGH, M. Naturaleza y Ciudad. Planificación Urbana y Processos Ecológicos. Barcelona: Gustavo Gili, 1998.

INSTITUTO BRASILEIRO DE GEOGRAFIA E ESTATÍSTICA. Diretoria de Pesquisas DPE - Coordenação de População e Indicadores Sociais - COPIS. 2014.

Disponível em: <http://cod.ibge.gov.br/6xk> Acesso em: 12 abr. 2015.

INSTITUTO DE PESQUISAS TECNOLÓGICAS. Ordenamento Territorial Geomineiro. Área: Região Metropolitana do Vale do Paraíba. São Paulo: Bases Preliminares - Relatório Final, SEE/SSM, 2015.

LEON, T. Cavas, as crateras irrecuperáveis do Vale do Paraíba. Jornal eletrônico 0 ECO, 2013 Disponível em: <oeco.org.br/fotografia/27094-cavas-as-craterasirrecuperaveis-do-vale-do-paraiba>. Acesso em: 2 mar. 2015.

RIBEIRO, R. M. A exploração de cavas de areia no Vale do Paraíba: atores e conflitos - estudo de caso de Jacareí e São José dos Campos. 2010. $185 f$.

Dissertação (Mestrado em Planejamento Urbano e Regional) - Universidade do Vale do Paraíba, São José dos Campos, 2010.

RONDINO, E. Áreas Verdes como redestinação de áreas degradadas pela mineração: Estudo de casos nos municípios de Ribeirão Preto, Itu e Campinas, 
Estado de São Paulo. 2005. 126f. Dissertação (Mestrado em Agronomia) Universidade de São Paulo, Piracicaba, 2005.

SANTOS, M. Espaço e Sociedade. Petrópolis: Vozes. 1979.

SANTOS, M. Espaço e método. São Paulo: Nobel, 1985.

SÃO PAULO. Ministério Público do Estado. Mineração por cavas submersas:

Atualização da análise temporal da mineração na Várzea do Rio Paraíba do Sul-SP, no período entre os anos de 1986 a 2002/2004 para o ano de 2008. 2008.

SÃO PAULO. Assembleia Legislativa do Estado. Ações para regularizar extração de areia no Paraíba do Sul. 2006. Disponível em:

<http://www.al.sp.gov.br/noticia/?id=286080>. Acesso em: 25 mar. 2016.

SILVA, S. S. Milton Santos: Concepções de Geografia, Espaço e Território. 2009. 99f. Dissertação (Mestrado em Geografia) - Universidade Estadual do Oeste do Paraná. Francisco Beltrão, 2009.

VILLAÇA, F. Espaço intra-urbano no Brasil. São Paulo: Studio Nobel/FAPESP, 1998. 